\title{
LETRAMENTO E CONHECIMENTO LINGUÍSTICO-GRAMATICAL SOBRE GÊNEROS
}

\author{
LITERACY AND LANGUAGE-GRAMMATICAL \\ KNOWLEDGE ABOUT GENDERS
}

\section{Luiz Carlos Travaglia}

\section{RESUMO}

O objetivo deste artigo é continuar uma abordagem já iniciada (TRAVAGLIA, 2015) sobre a relação entre gramática da língua/conhecimento linguístico e o letramento. Aqui aborda-se basicamente a questão do conhecimento linguístico implicado no uso dos gêneros e como esse conhecimento linguístico é importante no letramento, já que este é visto como o uso de textos escritos (produção e compreensão) em situações de ação social pela linguagem.

Palavras-chave: Letramento. Gêneros textuais. Ensino de Língua Materna.

\section{ABSTRACT}

The objective of this article is to continue an approach already begun (TRAVAGLIA, 2015) on the relation between language grammar / linguistic knowledge and literacy. Here we address basically the question of the linguistic knowledge implied in the use of the genres and how this linguistic knowledge is important in literacy, since this is seen as the use of written texts (production and comprehension) in situations of social action through language.

Keywords: Literacy. Textual genres. Mother tongue teaching.

\section{PORQUE GÊNEROS TEXTUAIS E LETRAMENTO SE CORRELACIONAM}

Como já se sabe, alfabetização e letramento são processos interligados na aquisição da modalidade escrita da língua. A alfabetização refere-se à "aprendizagem de um conhecimento notacional: a escrita alfabética" (PCNs, 2000, p. 33), ou seja, o domínio do sistema alfabético e ortográfico, a aquisição do sistema convencional da escrita (Cf. Soares-2008). O letramento, é a "aprendizagem da linguagem que se usa para escrever" (PCNs, 2000, p. 33), a aquisição da "possibilidade de compreender e produzir textos em linguagem escrita" (p. 33), considerando as características discursivas da linguagem (p. 34), para uma maior participação social pelo estabelecimento de relações interpessoais pela significação do mundo e da realidade (p. 24). Para Soares (2008) o letramento é entendido como o desenvolvimento de habilidades, comportamentos e práticas de uso competente do sistema convencional da escrita na produção e compreensão de textos dentro de práticas sociais em que a leitura e a escrita estejam envolvidas. Como dissemos em Travaglia (2015),

\footnotetext{
${ }^{1}$ Doutor em Linguística pela Universidade Estadual de Campinas (Campinas/Brasil). Professor na Universidade Federal de Uberlândia (Uberlândia/Brasil). E-mail: lctravaglia@ufu.br.
} 
[...] o letramento envolve uma gama bastante grande de conhecimentos linguísticos ou gramaticais como se queira dizer, relacionados ao domínio da variedade escrita da língua, embora muitos deles sirvam também à competência de uso da variedade oral. Estes conhecimentos linguísticos terão que ser trabalhados com os alunos de forma explícita ou não, mas de modo a que eles sejam capazes de controlar seu uso por uma reflexão linguística para constituição e compreensão dos textos. Dessa forma o letramento vai exigir um trabalho com o conhecimento linguístico em conjunto com as atividades que o professor desenvolva para o aluno adquirir a variedade escrita da língua. Neste caso se pressupõe que, ao chegar à escola, ele já domine pelo menos a variedade oral familiar. Este conhecimento terá então o papel de ajudar o aluno a:

1) alcançar progressivamente um domínio mais profundo, mais amplo e mais consciente de recursos da língua em todos os planos (fonológico, morfológico, sintático, semântico e pragmático); níveis (lexical, frasal e textual-discursivo) ${ }^{2}$ e das modalidades (oral e escrito) da língua;

2) conscientizar-se da existência das variedades linguísticas e de suas características básicas em termos explícitos, mas essencialmente em termos da prática de uso situado dessas variedades (TRAVAGLIA, 2015, p. 160).

O letramento é, na verdade, um processo que, para nós, nunca está concluído, pois em função da riqueza da língua há sempre mais recursos de todos os seus planos, níveis e variedades, cujo domínio o usuário dessa língua terá que desenvolver, para uso na modalidade escrita, mas também na oral.

Em diversos momentos já falamos de como trabalhar com recursos desses vários planos, níveis e variedades da língua. Neste texto buscamos focar no conhecimento linguístico que se tem de adquirir para usar um gênero em termos dos cinco parâmetros que propusemos como caracterizadores dos gêneros, bem como de outras categorias textuais, como os tipos (TRAVAGLIA, 2007): seu conteúdo temático, sua estrutura composicional (principalmente sua superestrutura, mas também outros aspectos, conforme sejam pertinentes em cada gênero), seu estilo (características da superfície linguística, sempre em correlação com o gênero e os tipos e espécies que o constituem ${ }^{3}$ e outros parâmetros), seus objetivos e funções sociocomunicativas, suas condições de produção. Estes são parâmetros caracterizadores dos gêneros em sua forma e funcionamento discursivo.

Todos esses fatos constituem um vasto conhecimento linguístico sem o qual não se terá um letramento efetivo e de qualidade, já que este não existe enquanto não se atinge uma habilidade e competência de produção e compreensão de textos dentro de práticas sociais em que a leitura e a escrita estejam envolvidas. Em Travaglia (2015), sugerimos que um letramento completo inclui o desenvolvimento de

Habilidades relativas a categorias de textos (tipos/subtipos, gêneros, espécies):

a) perceber qual é a categoria de texto (especialmente o gênero) adequado à interação que se realiza;

b) construir o texto atendendo às características formais e funcionais de ação social do gênero em uso (TRAVAGLIA, 2015, p. 164-165).

Por essa razão, consideramos pertinente dizer algo destacando os gêneros como parte fundamental da gramática da língua e essencial para um letramento real e de qualidade, uma vez que os gêneros de texto são um tipo de recurso linguístico que condiciona a construção dos textos e seu uso situado. Não se trata de um conhecimento na dimensão de classificação de gêneros, mas sim de sua constituição e funcionamento, focando no fato de que gêneros são "formas de conhecimento cultural que emolduram e medeiam conceitualmente a maneira como entendemos e agimos tipicamente em diversas situações" (BAWARSHI; REIFF, 2013, p. 16).

\footnotetext{
2 - O termo discursivo foi acrescentado à citação como uma complementação de algo que faltou no original citado, uma vez que o discursivo foi registrado em Travaglia (2015) um pouco adiante da citação.

3 - Sobre a constituição de gêneros por tipos/sutipos e espécies sugerimos consultar Travaglia (2007) e (2007b).
} 
Os gêneros são instrumentos de comunicação em sociedade, de interação pela linguagem. São o que efetivamente usamos em termos de textos quando agimos em múltiplas e diferentes comunidades discursivas. É por meio dos gêneros que nos comunicamos. Cada grupo ou área social cria gêneros que são apropriados para "uma maior participação social pelo estabelecimento de relações interpessoais pela significação do mundo e da realidade" (PCNs-2000, p. 24), para realizar ações que são pertinentes e significativas para a comunidade. Os gêneros têm, inclusive, uma dimensão identitária para os membros de cada comunidade discursiva. Saber usar um gênero é de certa forma pertencer à comunidade que o utiliza de modo corrente.

Os gêneros se contam aos milhares o que cria um problema para o professor quando se trata de decidir com que gêneros trabalhar em sala de aula. A seguir falamos um pouco sobre isso.

Geralmente os usuários adquirem a habilidade de uso de um gênero por meio da prática social necessária a suas vidas, inclusive a profissional. Por isso mesmo, tem-se enfatizado que a escola tem que considerar tais condições discursivas de produção ou o aprendizado do gênero não será efetivo e sem ele não se terá uma boa interação.

Quanto à escolha de com que gêneros trabalhar repetimos aqui o que foi dito em Travaglia (2011)

A partir dos critérios propostos pelos PCNs (Brasil, 1998, 26) e por Travaglia (2002a, 211-213) propomos uma lista de seis critérios que parecem poder orientar a escolha dos gêneros com que trabalhar na escola: a) Trabalhar tanto com gêneros orais quanto com gêneros escritos, dando a eles importância igual; b) A utilização que o aluno necessariamente fará de cada gênero em sua vida, independentemente de sua profissão; c) Trabalhar com os gêneros de ocorrência mais frequente e/ou constante na vida das pessoas; d) Trabalhar com textos tanto de uso privado, quanto com os de uso público, observados os demais critérios; e) Tendo em vista a plena participação na sociedade letrada, deve-se optar por textos de gêneros que "podem favorecer a reflexão crítica, o exercício de formas de pensamento mais elaboradas e abstratas, bem como a fruição estética dos usos artísticos da linguagem"; f) E finalmente, lembrando que os tipos são as categorias de textos que compõem os gêneros, trabalhar com tipos que em nossa pesquisa chamamos de fundamentais porque entram na composição de quaisquer outros textos, isto é, tipos que entrem na constituição, se não de todos, da maioria dos gêneros. Nossa pesquisa tem demonstrado que este tipos são a descrição, a dissertação, a injunção, a narração e o argumentativo "stricto sensu".

Este último critério implica, sem dúvida, um aspecto importante do ponto de vista pedagógico, pois, se há categorias de texto que representam habilidades básicas para a constituição de textos de quaisquer gêneros, podemos organizar o ensino em torno de tais categorias, pois isto, mais ou menos independemente dos gêneros que forem trabalhados nas atividades de ensino/aprendizagem em sala de aula, estaria instrumentalizando os alunos para a produção e a compreensão de textos de quaisquer gêneros. Esta possibilidade parece bastante pertinente uma vez que, ao fazer uma seleção de gêneros, não conseguiremos trabalhar nos doze anos de Ensino Fundamental e Médio, nada além do que entre 50 e 100 gêneros (TRAVAGLIA, 2011, p. 513).

Não só para essa questão da escolha dos gêneros com que trabalhar em sala de aula, mas também para outros fatores que consideramos importante considerar no trabalho com gêneros, remetemos o leitor a Travaglia (2011). O professor vai se deparar com outras escolhas ao trabalhar com os gêneros. Uma delas, por exemplo, é se, ao trabalhar com os gêneros devemos ou não abordar sua caracterização teórica e se sim, de que forma? Devemos fazer uma abordagem teórico-descritiva ou semântico-funcional (TRAVAGLIA, 2015) e ainda chamar a atenção para o funcionamento discursivo do gênero nas situações efetivas de interação social? Vamos trabalhar com uma abordagem mista?

Apenas para que se tenha uma ideia mais concreta do que estamos propondo, apresentamos a seguir algumas considerações em torno de um gênero específico: o contrato. 


\section{UM GÊNERO NO LETRAMENTO}

Tendo explicitado que o conhecimento linguístico e, especificamente, o conhecimento linguístico sobre gêneros é fundamental para o letramento, passamos a tecer considerações em torno do exemplo dos "contratos" que são de um gênero essencialmente escrito.

Ao selecionar, de acordo com critérios adotados, um gênero para trabalhar com os alunos, e tendo decidido o tipo de abordagem que se fará, o professor precisa ter uma caracterização básica do gênero em foco para estruturar atividades que levem o aluno a aprender o gênero ou aperfeiçoar seu uso, caso já o utilize.

Ao trabalhar com os alunos a compreensão e a produção dos contratos, levá-los a perceber aspectos como:

1) o contrato assim como o acórdão, o acordo, o convênio e a convenção tem o objetivo, a função comunicativa básica de estabelecer uma concordância (TRAVAGLIA, 2007, 61) entre um grupo de interessados ou entre duas ou mais partes representadas por pessoa(s) ou grupo(s) de pessoas, ou empresas ou instituições. O que muda são as condições de produção: o contrato se estabelece entre pessoas (individualmente ou em grupos) ou entre pessoas e empresas. Cada uma das partes concorda em fornecer a outra determinados elementos, segundo certas condições. Por exemplo, um apartamento para morar e em contrapartida o outro dará ao primeiro uma quantia mensal, chamada de aluguel. Os contratos podem ser de espécies diferentes, conforme o que as duas partes estão "trocando", ou seja o objeto do contrato. Assim temos contratos: de locação, de prestação de serviços, de empréstimo, de compra e venda, de corretagem, de transporte, de comodato (que é o empréstimo gratuito de algo não consumível e que deve ser devolvido no prazo combinado), etc. Os contratos têm sempre uma natureza jurídica. O acordo por sua vez é uma concordância que põe fim a uma desavença por qualquer razão, com intermediação jurídica ou não. $\mathrm{O}$ acórdão é uma concordância entre um grupo de juízes (com unanimidade ou não) sobre a sentença a ser proferida em um determinado processo em que houve recurso a uma segunda instância. O convênio é um tipo de acordo feito entre instituições públicas ou privadas, para atingir um objetivo comum, estabelecendo uma parceria. A convenção é um tipo de acordo que se estabelece sobre determinada atividade ou assunto e registra entendimentos prévios e normas baseadas na experiência, para reger tal atividade ou assunto. É o caso, por exemplo, das convenções de condomínio que estabelecem normas para o convívio em conjuntos vinculados de moradia com áreas privativas e comuns; e também de convenções coletivas de trabalho. Aqui já falamos dos objetivos ou funções do gênero e de suas condições de produção (quem produz, para quem, em que circunstâncias);

2) o conteúdo temático de um contrato será, portanto, sempre uma concordância sobre o fornecimento de algo por uma das partes e a contrapartida pela outra parte e quais as condições dessa "troca";

3) na estrutura composicional de um contrato vamos destacar sua superestrutura que deve conter várias partes ou categorias. Vamos indicar essas partes ou categorias da superestrutura de um contrato, usando a fonte Arial Black, especificando-as para especificá-las, já em um modelo de contrato de locação, que é expressão de um conhecimento linguístico. Especificamos em itálico a indicação do que deve ser colocado em cada espaço do modelo. 


\section{(1) Modelo de contrato}

a) Título do contrato, em que se especifica o tipo de contrato

\section{CONTRATO DE LOCAÇÃO DE IMÓVEL ${ }^{4}$}

b) Qualificação das partes (Genericamente contratante e contratado que conforme o tipo de contrato recebem especificações diferentes como no contrato de locação: "locador" e "locatário")

Os signatários deste instrumento,

de um lado,

nome

portador do $\mathrm{RG} \mathrm{n}^{\circ}$

Bairro _(nome do bairro)

e de outro

nome

(comerciário), portador do $\mathrm{RG} \mathrm{n}^{\circ}$

nacionalidade (brasileiro), estado civil (casado), profissão , e do CPF $\mathrm{n}^{\circ}$ (nome do bairro) cidade - estado, doravante designado nacionalidade (brasileiro), estado civil (casado), profissão (engenheiro), e do $\mathrm{CPF} \mathrm{n}^{\circ}$ residente e domiciliado à endereço Bairro residente e domiciliado à

LOCATÁRIO;

\section{c) Especificação do objeto do contrato}

têm justo e contratado o seguinte, que mutuamente convencionam, outorgam e aceitam, a saber: O primeiro nomeado, aqui designado "L O C A D O R", sendo proprietário de uma casa/ um apartamento situada/situado à Rua endereço__ $\quad n^{o}$ complemento bairro em cidade estado dá este imóvel em locação ao segundo, aqui designado "LOCATÁRIO", mediante as cláusulas e condições seguintes:

\section{d) Especificação das condições}

$\mathbf{1}^{\mathbf{a} 5}$ - O prazo de locação é de (Coloca o prazo do contrato: $X$ meses ou anos) a iniciar-se em _dia___mês__ano e a terminar em_dia_l_mês_l _ ano_ data em que o LOCATÁRIO se obriga a restituir o imóvel desocupado ou de outra forma a renovar expressamente o contrato caso vier a permanecer no imóvel. Nesse caso o valor do aluguel será reajustado de acordo com o índice oficial para tal fim indicado pelo governo, ou na falta deste, de acordo com índice acordado pelas partes;

$\mathbf{2}^{\mathbf{a}}$ - O valor do aluguel mensal será de $\mathrm{R} \$$ 00 valor por extenso ) que o LOCATÁRIO se compromete a pagar pontualmente no dia ( dia

por extenso ) de cada mês, na residência do LOCADOR ou outra forma que vier a ser acordada entre os mesmos. Após esse dia o LOCATÁRIO ficará sujeito a multa de 2\% (dois por cento) e juros de mora de $0,1 \%$ (meio por cento) ao dia;

$\mathbf{3}^{\mathbf{a}}$ - Os consumos de luz, água, telefone e gás, assim como todos os encargos e tributos (inclusive IPTU, este juntamente com o aluguel de cada mês, no caso de parcela mensal ou integralmente em uma só vez, conforme opção do LOCATÁRIO) que incidam ou venham a incidir sobre o imóvel, conservação, seguro e outras decorrentes de Lei, assim como suas respectivas majorações, ficam a cargo do LOCATÁRIO e, seu não pagamento na época determinada acarretará a rescisão do presente contrato;

$4^{\mathrm{a}}$ - O LOCATÁRIO, salvo as obras que importem na segurança do imóvel obriga-se por todas as outras devendo trazer o imóvel locado em boas condições de higiene e limpeza com aparelhos sanitários e de iluminação, pinturas, papéis, telhas, vidraças, mármores, fechos, fechaduras, torneiras,

\footnotetext{
4 - Há contratos de locação de aparelhagens, ferramentas, utensílios e adornos para festas, etc.

5 - Nos contratos pode-se apenas colocar o número da cláusula ou colocar a palavra dizendo "Cláusula 1", "Cláusula 2", etc.
} 
pias, banheiros, ralos e demais acessórios em perfeito estado de conservação e funcionamento, para assim restituí-los quando findo ou rescindido este contrato sem direito a indenização ou retenção por quaisquer benfeitorias, ainda que necessárias, as quais ficarão desde logo incorporadas ao imóvel. Além disso o LOCATÁRIO obriga-se, ao entregar o imóvel, a pintá-lo, independentemente do tempo de locação com tinta látex acrílica de primeira qualidade (ou equivalente existente no mercado, caso deixe a atual de ser produzida), sendo o serviço realizado por profissional escolhido de comum acordo por LOCADOR e LOCATÁRIO;

$\mathbf{5}^{\mathbf{a}}$ - Obriga-se o LOCATÁRIO a satisfazer todas as exigências dos poderes públicos a que der causa, não motivando elas a rescisão deste contrato;

$\mathbf{6}^{\mathbf{a}}$ - Não é permitido ao LOCATÁRIO a transferência deste contrato, nem a sub-locação, cessão ou empréstimo total ou parcial do imóvel, sem prévio consentimento por escrito do LOCADOR, devendo no caso deste ser dado, agir oportunamente junto aos ocupantes, a fim de que o imóvel esteja desimpedido nos termos do presente contrato.

$7^{\mathbf{a}}$ - Igualmente não é permitido fazer modificações, ou transformações no imóvel, sem autorização escrita do LOCADOR, mesmo que representem benfeitorias;

$\mathbf{8}^{\mathbf{a}}$ - O LOCATÁRIO desde já faculta ao LOCADOR ou seu representante, examinar, vistoriar o imóvel locado, quando o LOCADOR entender conveniente;

$9^{\text {a }}$ - No caso de desapropriação do imóvel locado, ficará o LOCADOR desobrigado por todas as cláusulas deste contrato, ressalvada ao LOCATÁRIO tão somente a faculdade de haver do poder desapropriante a indenização a que, porventura, tiver direito;

$\mathbf{1 0}^{\mathbf{a}}$ - Nenhuma intimação do serviço sanitário será motivo para o LOCATÁRIO abandonar o imóvel ou pedir rescisão deste contrato, salvo procedendo vistoria judicial que apure estar a construção ameaçando ruir;

11 ${ }^{a}$ - Assina(m) também o presente contrato, como fiador(es) e principais pagadores, solidariamente com o LOCATÁRIO, por todas as obrigações neste estipuladas, as pessoas abaixo identificadas, cuja responsabilidade perdurará até a entrega real e efetiva das chaves do imóvel locado, mesmo ultrapassando o prazo do contrato e que haja reajustamento dos aluguéis. Os fiadores oferecem ainda em garantia os imóveis abaixo relacionados livres de quaisquer ônus, hipotecas ou financiamentos e que não poderão alienar sem oferecer antes ao LOCADOR outro imóvel como substituto na garantia oferecida, sob pena de incorrer nas penas da lei:

Primeiro fiador: Qualificação do fiador: nome, nacionalidade, estado civil, profissão, documentos (RG e CPF) endereço

Imóvel de garantia: Especificação do imóvel de garantia com seus dados de localização e registros nos cartórios, sobretudo o de registro de imóveis

\section{Segundo fiador: (Idem ao primeiro)}

Imóvel de garantia: (Idem ao primeiro)

$1^{\mathbf{a}}$ - No caso de morte, falência ou insolvência ou mudança de domicílio dos fiadores, o LOCATÁRIO se obriga a, dentro de no máximo 30 (trinta) dias, a dar substituto idôneo, a critério do LOCADOR, sob pena de incorrer na cláusula seguinte;

$\mathbf{1 3}^{\mathbf{a}}$ - Fica estipulada a multa de _Número em algarismos arábicos___ _ Número por extenso___ aluguéis na qual incorrerá a parte que infringir qualquer cláusula deste contrato, com a faculdade para a parte inocente, de poder considerar simultaneamente rescindida a locação, independentemente de qualquer formalidade; 
$14^{\text {a }}$ - O imóvel objeto deste contrato destina-se exclusivamente a fins (residenciais, comerciais, industriais, etc., conforme o caso) não podendo sua destinação ser mudada sem o consentimento expresso por escrito do LOCADOR;

$15^{\mathbf{a}}$ - Não ficam compreendidas na multa da cláusula $13^{\mathrm{a}}$, devendo ser pagas à parte pelo LOCATÁRIO, todas as despesas a que o proprietário for obrigado em consequência de quaisquer estragos ocasionados ao imóvel e suas instalações, bem como as despesas eventuais com modificações feitas no imóvel pelo LOCATÁRIO, mesmo quando autorizadas, mas que não poderão permanecer no imóvel como benfeitorias a critério do LOCADOR;

\section{e) Estabelecimento das condições legais de operacionalização}

$16^{\mathbf{a}}$ - Tudo quanto for devido em razão do presente contrato, e que não comporte o processo executivo, será cobrado em ação competente, ficando a cargo do devedor, em qualquer caso, os honorários advocatícios que o credor constituir para ressalva de seus direitos;

$17^{\mathrm{a}}$ - Para todas as questões oriundas deste contrato, será competente o foro da situação do imóvel, com renúncia de qualquer outro, por mais especial que se apresente e quaisquer que sejam os domicílios dos contratantes;

\section{f) Assinaturas para validação do contrato}

$1 \mathbf{1 8}^{\mathbf{a}}$ - Assim, por estarem justos e contratados, assinam o presente contrato em 02 (duas) vias, de igual teor, em presença das testemunhas abaixo, destinando-se uma via para cada uma das partes interessadas.

Cidade onde se realiza o contrato, data (dia_de_mês__de__ano__).

A seguir colocam-se as assinaturas de: a) locador(a), locatário(a), cônjuge do locatário(a) com os respectivos CPFs; b) fiadores e cônjuges dos fiadores com os respectivos $C P F s$ e c) de testemunhas com seu CPF e endereço.

É preciso lembrar que este modelo é básico e corrente, mas que, como com todo gênero, pode haver variações dependendo da situação específica de interação e do que foi acordado entre as partes. Assim, por exemplo, as cláusulas $11^{\mathrm{a}}$ e $12^{\mathrm{a}}$ podem ser retiradas, se o locador dispensar fiadores ou, elas podem ser modificadas, se os fiadores forem substituídos por seguro fiança ou depósito caução ou título de capitalização (Nesse caso, é óbvio, não há assinatura de fiadores e respectivos cônjuges). Evidentemente outras cláusulas podem ser acrescentadas de acordo com a situação ou modificadas, se, por exemplo, mudar a lei do inquilinato. Isto leva o aluno a perceber que um gênero não é isolado e frequentemente faz parte de um conjunto de gêneros, organizados ou não em uma rede de gêneros. A assinatura por testemunhas é opcional, mas desejável do ponto de vista legal.

4) Quanto às características da superfície linguística os contratos, e em particular o de locação de imóvel do exemplo acima, apresentam um número significativo de léxico e frases prototípicas que são elementos caracterizadores do contrato, alguns inclusive de origem legal. Assim temos:

- têm justo e contratado

- mutuamente convencionam, outorgam e aceitam

- dá este imóvel em locação

- o prazo de locação é de

- o valor do aluguel mensal será 
- ficam a cargo do LOCATÁRIO

- obriga-se

- quando findo ou rescindido este contrato

- indenização ou retenção

- transferência deste contrato, nem a sub-locação, cessão ou empréstimo total ou parcial do imóvel

- sem prévio consentimento por escrito do LOCADOR

- desapropriação do imóvel locado

- Assina $(m)$ também o presente contrato, como fiador(es) e principais pagadores, solidariamente com o LOCATÁRIO

- Fica estipulada a multa de

- O imóvel objeto deste contrato destina-se exclusivamente a fins (residenciais, comerciais, industriais, etc., conforme o caso)

- será cobrado em ação competente

- os honorários advocatícios que o credor constituir para ressalva de seus direitos

- será competente o foro da situação do imóvel

- por estarem justos e contratados

- assinam o presente contrato em 02 (duas) vias, de igual teor, em presença das testemunhas abaixo, destinando-se uma via para cada uma das partes interessadas.

Temos acima uma caracterização básica de um contrato, e mais especificamente de um contrato de locação, que representa um conhecimento da gramática da língua no plano textual-discursivo e que um usuário da língua tem de dominar se quiser produzir e compreender textos pertencentes ao gênero em foco. Todavia não se esboçou ainda uma proposta de como trabalhar tudo isso com o aluno, embora a caracterização do gênero já deixe perceber uma série de atividades a serem desenvolvidas.

Como dissemos, o trabalho em sala de aula pode ser feito por uma via teórico-descritiva ou por uma via semântico-funcional ou uma via mista das duas abordagens. Na verdade, há uma preferência pelo trabalho nessa via mista, mas queremos salientar que não é muito produtivo, em termos do estabelecimento de novas habilidades do usuário da língua, o uso apenas ou sobretudo da abordagem teórico-descritiva, embora ela seja necessária como um conhecimento do professor para subsidiar a constituição das atividades em sala de aula.

Cremos que, sem qualquer dúvida, o professor pode começar apresentando alguns exemplares de contratos reais, inclusive de espécies distintas; levar o aluno a entender os contratos, inclusive a linguagem em parte jurídica dos mesmos (É a parte da compreensão de textos). Ao buscar a compreensão ele já irá registrando o léxico e os torneios próprios do gênero observando seu estilo, ou seja, suas características linguísticas de superfície. Os alunos devem também observar que o conteúdo temático em termos de tipo de informação é sempre um só: quem contrata (contratantes) o que (objeto de contrato) sob que condições. Isto se reflete nitidamente nas partes ou categorias constituintes da superestrutura do contrato que, quando elicitada, ajuda o aluno no controle de elementos fundamentais para a efetiva interação pela linguagem em situações sociais. Eles podem detectar o que há de comum e de diferente entre as diversas espécies de contrato a que nos referimos no item 1 da caracterização dos contratos, o que os prepara para uma maior gama de situações diferentes de ação social pela linguagem, por meio da produção e compreensão de textos que é, em última instância, a competência comunicativa que temos como objetivo desenvolver no ensino de língua. 
A atividade de produção de contratos deve acontecer e ser controlada pelo conhecimento levantado na observação de exemplos e modelos, pois como sabemos, na formulação do texto, o gênero sobredetermina ou determina todos os elementos discutidos em sua caracterização. Os passos dessa produção variam conforme os diferentes casos, mas atenderá sempre as recomendações da metodologia do ensino de produção textual, principalmente em termos de etapas: identificação do gênero adequado à situação ou proposição da situação apropriada para o gênero que se quer seja produzido; seleção e organização das informações de acordo com o conteúdo temático do gênero e também em termos do(s) objetivo(s) que se pretende alcançar com o texto; produção do texto; revisão; utilização em situações o mais concretas possível.

\section{CONSIDERAÇÕES FINAIS}

Esperamos que essa breve exposição tenha evidenciado e concretizado, da forma mais clara possível, que o conhecimento de gêneros tem um forte papel no letramento dos usuários da língua. Além disso, esperamos ter evidenciado o tipo de conhecimento linguístico-gramatical que está envolvido nesse caso, e que será objeto de ensino/aprendizagem. Alguns ou muitos podem não concordar que o que expusemos aqui sobre gêneros, exemplificando com os contratos, pertence à gramática da língua. Para nós fazem parte dessa gramática, como dissemos, no nível textual-discursivo. Todavia independente da postura sobre essa questão do que faz ou não parte da gramática de uma língua, parece-nos evidente que, sem tal conhecimento, o letramento não se configura como tal, nem se completa. Não considerar no letramento a questão das categorias de texto, principalmente os gêneros, é fadar o trabalho de ensino/aprendizagem em sala de aula ou em qualquer outra agência a falhar no desenvolvimento da competência comunicativa de nossos alunos, simplesmente porque não temos como produzir e compreender textos sem produzir e compreender gêneros.

\section{REFERÊNCIAS}

BAWARSHI, Anis S.; REIFF, Mary Jo. Gênero: história, teoria, pesquisa, ensino. São Paulo: Parábola, 2013.

PARÂMETROS CURRICULARES NACIONAIS: língua portuguesa. Secretaria de Educação Fundamental. $2^{\mathrm{a}}$ ed. Rio de Janeiro: DP\&A, 2000.

SOARES, Magda. Alfabetização e letramento. 5. ed. São Paulo: Contexto, 2008.

TRAVAGLIA, Luiz Carlos. Letramento e conhecimento linguístico. Letras \& Letras, Uberlândia, Instituto de Letras e Linguística / Universidade Federal de Uberlândia, v.31, n.3, p. 158-172, (jul./dez. 2015).

TRAVAGLIA, Luiz Carlos. O que é um ensino de Língua Portuguesa centrado nos gêneros? In: Anais... Anais do SIELP. v. 1, n. 1. Uberlândia: EDUFU, 2011. p. 509- 519.

TRAVAGLIA, Luiz Carlos. Sobre a possível existência de subtipos. Anais... Anais do VI Congresso Internacional da ABRALIN. Organizador: Dermeval da Hora. João Pessoa, 2009. p. 2632-2641.

TRAVAGLIA, Luiz Carlos (2003). Tipelementos e a construção de uma teoria tipológica geral de textos. In: FÁVERO, Leonor Lopes; BASTOS, Neusa M. de O. Barbosa; MARQUESI, Sueli Cristina (org.). Língua Portuguesa pesquisa e ensino - Vol. II. São Paulo: EDUC/FAPESP, 2007, p. 97- 117. 
TRAVAGLIA, Luiz Carlos. A caracterização de categorias de textos: tipos, gêneros e espécies. Alfa: Revista de Lingüística, v. 51, p. 39-79, 2007.

TRAVAGLIA, Luiz Carlos. Das relações possíveis entre tipos na composição de gêneros. In: Anais... $4^{\circ}$ Simpósio Internacional de Estudos de Gêneros Textuais (IV SIGET), 2007, Tubarão: Universidade do Sul de Santa Catarina - UNISUL, 2007b. v. 1. p. 1297-1306. 